finding lodgment on the valves. Here they produced vegetations some of which by embolism were carried to the various organs affected, including the brain and spinal cord. Such distribution of the diphtheria bacillus is thought to be extremely rare. Indeed, malignant endocarditis is an extremely rare complication of any of the usual infective fevers. Cerebro-spinal symptoms in association with malignant endocarditis have been observed, of course, but I am not aware that the diphtheria bacillus has been demonstrated as the infecting organism in any recorded case previous to the present communication. If any such cases have been recorded previously the rarity of the condition appears to me to justify the present record.

Southend.

\section{A CASE OF DOUBLE OPTIC NEURITIS SYMPTOMS OF CEREBELLAR TUMOUR; COMPLETE RECOVERY.}

\section{BY CHARLES HIGGENS, F.R.C.S. ENG.}

A BOY, aged six years, was brought to see me on May 22 nd, 1894. I was told that it had been accidentally discovered that he could not see properly and that six weeks before his sight appeared to be perfect. He could distinguish none of the test types. In his right eye the optic disc was swollen and its outline was blurred. The left disc was red but its outline was well defined and it was not swollen. He had some nervous symptoms resembling chorea; there was no albumin in the urine. I advised that he should consult a physician and did not see him agxin at that time. Two years later, on June $9 \mathrm{tb}, 1896$, I saw the patient's mother, who told me that he became quite blind but began to recover slowly and eventually got quite well. On Sept. 19th, 1904, I saw him again. He was myopic and $I$ thought that his discs were rather pale. His vision was :-

$$
\text { Right eye } \frac{6}{36} \mathrm{c}-\frac{75 \mathrm{cyl} .}{2 \mathrm{spn} .} \frac{6}{6} ; \text { left eye } \frac{6}{36} \mathrm{c}-\frac{75 \mathrm{cyl} .}{1 \cdot 50 \text {-pn. }} \frac{6}{6} \text {. }
$$

I saw him again on May 8th, 1907. He was a tall well-set-up fellow of 19 years and appeared to be perfectly healthy. His discs were rather pale ; his myopia had increased by $1 \mathrm{D}$. but his vision was $\frac{6}{5}$ with correcting glasses and both fields were normal. He told me that after I saw him in 1894 he was taken to Dr. Ferrier. I wrote to Dr. Ferrier and asked him if he would look up his notes of the case and let me know what he made of it, and he very kindly wrote to me as follows: "I first saw the boy in May, 1894; he then had double optic neuritis, more marked in the right eye, and some symptoms of cerebellar disease. In Jaly of that year the cerebellar symptoms were marked, but the neuritis had disappeared and the discs were somewhat pale. He could only read J.20. In March, 1895, his vision was $\frac{6}{12}$. He appeared otherwise well. My diagnosis was cerebellar tumour? Might it be a tubercular nodule which has become cretified?"

Remarks.-The duration of the boy's illness appears to have been under 12 months; as far as was known he was quite well six weeks before he saw me in May, 1894, and from Dr. Ferrier's report he had quite recovered by March, 1895 ; his vision being only 6 was probably accounted for by a low degree of myopia.

The case is interesting chiefly on account of the complete recovery which took place; my experience of similar ones is that they almost invariably go blind and that some of them die, though often years after the appearance of the first symptoms. The patients wander about from hospital to hospital, or from one medical man to another, blind and staggering, and it is rare for the surgeon or physician who first sees them to see the end of them. I have been in the habit of pointing out blind staggering children and calling them cerebellar children, and in one or two cases in which I have seen a necropsy tumour in the cerebellum was found. In the case reported Dr. Ferrier's suggestion that it might be a tuberculous nodule which has become cretified is probably correct, but there is the possibility of congenital syphilis, though the patient shows no signs of it and I have not gone into the history.

Treatment, so far as I know, does no good, but one has to do something and if a case recovers under any kind of treatment so much the better. I have trusted mainly to mercary and iodide and in two cases have trephined with very marked relief, which was, however, only temporary, and the last time I siw the patients they appeared to be neither better nor worse for the operation.

Brook-street, $W$.

\section{A CASE OF LAND SCURVY}

OCGURRING IN A PATIENT AFTER A PROLONGED PERIOD AS AN IN-PATIENT IN A HOSPITAL AND AS A COMPLICATION OF A FISTULA IN ANO.

BY J. BERNARD DAWSON, M B., B S. LOMD., M.R C.S. ENG., L.R.C.P. LOND.,

HOUSE SURGEON TO ST. MARK'S HOSPITAL FOR DISEASES OF [HE RECTUM, CITY-ROAD, LONDON, E.C.

WHAT is the determining factor in the etiology of scirvy as yet remains a problem of medical science. Whether the theory of chronic ptomaine poisoning or whether that of dietetic error be the truth is undecided by those who have studied the subject especially, evidence seeming to be equally strong for both. Experimental information resolves itself into two classes, that resulting from laboratory wouk proper and that gleaned from the logbooks of Arctic anl other expeditions. The experiments of Harley and Jackson consisted in the feeding of apes with scorbutic and anti. scorbutic diets. Their results seem to be mitigated by the following facts: (1) that monkeys are not naturally carnivorous ; (2) that the tinned meats used were allowed to become tainted after preservation and not before, as is the case of the doubtful canned food found in the cheapest shops or in marine stores; and (3) that the digestive economy of the lower primates seems to be capable of dealing with putrescent food.

Briefly, the evidence derived from the reports of travellers during the past six years is as follows. 1. Dr. Koettlitz, who accompanied both the Nansen and the British National Antarctic Expeditions, reports in reference to the latter that there was very considerable trouble from disablement of the crew from scurvy, notwithstanding the fact that limejuice occupied a prominent position in the rations served out daily. It was found out on investigation that the preserved meat supplied for the expedition was not beyond reproach. 2. The Jackson-Harmsworth Arctic Expedition yielded some interesting facts. When the relief ship reached them it was with the intention of getting back before the ice closed. In this they were unsuccessful and the vessel with her crew remained 12 montbs. The men who were encamped on the ice lived during this year, as they had for many months before, upon fresh bears' meat, taking no limejuice ; they escaped any attacks of scurvy. Those who remained on the ship, refusing bears' flesh, chose to consume canned goods, often in an unwholesome condition, and notwithstanding the fact that a limejuice ration was served out daily, in the course of the year, all suffered and two died. 3. When Nansen and his companion Johansen left the Fram in their attempt to reach the Pole by sledge they were away 15 months, during which they existed entirely upon the flesh which fell to their skill as hunters and endured terrible hardship and toil, despite which they returned hale and whole.

In deducing from such statements as these it must be borne in mind that limejuice varies in quality and that the good intentions of the medical man in charge may have been rendered abortive by a sailor who disliked limejuice.

Such is the evidence of the ptomaine theory; evidence equally strong can be rallied upon the side of the dietetic supposition. 1. In $1795 \mathrm{Sir}$ Gilbert Blane introduced a limejuice ration into the navy's diet-sheet, with the result that scurvy, which had been very prevalent, became comparatively rare. It was, however, pointed out by Aitken in 1872 that Blane at the same time greatly improved the food generally. 2. Lieutenant-Colonel Hamilton reports the following. ${ }^{1}$ In 1885 he was in charge of the 23rd Pioneers, a Sepoy regiment, during an expedition among the hills of the northern frontier of India. Owing to the roguery of the native contractors the supply of vegetables arranged for failed. After a few weeks, in spite of the fact that fresh meat was abundant, scurvy showed itself among the troops. A small green cruciferous plant, found growing upon the hills, was then used as a spinach, with the result that rapidly the scurvy disappeared. 3. Dr. F. C. Sinclair in medical charge of a guano expedition to Walfisch Bay, S.W. Africa, states that his 400 Damara natives remained free from scurvy whilst the supply of freshly killed meat was good. His cattle, however, were carried off by rinderpest. The diet then consisted of peas, wheat-meal, porridge, rice, bread, biscuits, tea, and coffee, all sound food. In two months scurvy was prevailing among the negroes, 
with the exception of the native foremen who, sharing food with the whites, obtained a portion of the meat that was left. He, attributing the cause to the absence of meat, fresh or otherwise, pointed ont that the Damaras are in the habit of eating to engorgement of the putrid carcasses of hunted animals without apparent barm and certainly without scurvy Dr. Sinclair suggests that the transference of inland natives to the more rigorous climate of the coast, the conditions of the huts, and the heavy work in which they were engaged may have been accessory causes to the outbreak.

It will be seen from the above that there is weighty evidence upon both sides and in support of both theories.

Roberts in his text-book gives the following three possible causes of scurvy: (1) the absence of vegetables or their ingredients, probably the malates and lactates; (2) the presence of toxic material in the food; and (3) the presence of a specific organism in the food or introduced in some other way. In support of the first two theories evidence has been given above; in support of the last there seems little to be said except the parallel between scurvy and other diseases known to be produced by a specific organism.

In the case reported below there is nothing in the history of the patient or in the treatment which she received to lend support to either the first or the third augument; but the presence of a septic fccus around the rectum whence absorption takes place readily and freely suggests the possibility of the introduction of toxic material into the circulation. Whether such poisonous matter produced scorbutic symptoms or not it is difficult to determine, but since the other factors usually associated with an outbreak of scurvy were absent it is not unreasonable to suppose that its presence may have been the determining element. The reaction of the patient to treatment also is instructive, for she responded quickly to ordinary antiscorbutic measures. Apart from local treatment for the hæmorrhage, the patient was given the following: four half-drachm doses of calcium chloride in the course of 48 hours and a subcutaneous injection of a hundredth of a grain of ergotinine citrate, whilst two lemons and quantities of green vegetables were added to her diet. Under this treatment she speedily recovered in the manner detailed below. With the constitutional improvement the condition of her wound, which previously had been unsatisfactory and sluggish, underwent a corresponding change for the better. The use of calcium chloride was on account of the bleeding, and although unfortunately the alkaloid ergotinine was used as well, it is reasonable to accredit the rapid cessation of hæmorrhage partly at least to the use of the calcium salt. This is of interest because of the doctrine put forward by Sir A. E. Wright that the prominent feature in the pathology of scurvy is a reduced alkalinity of the blood, together with a reduced coagulability which allows of the spontaneous outpourings of that fluid. This view of the pathology of scurvy dovetails with the theory that its cause is absence of vegetable salts from the food ; for the citrates, tartrates, and malates of herbaceous food become changed into carbonates in the blood. As, however, the food which the patient had been in the habit of taking does not seem to have been in any way scorbutic, the suggestion that absorption from a septic focus was the initiating cause receives support. The history and progress of the case are as follows.

The patient was admitted to St. Mark's Hospital on April 6th, 1907, with an unhealed wound after two operations for fistula in ano which had left her without sphincteric control. There was also some prolapse of mucous membrane. She was a spare woman of pallid aspect, showing evidence of loss of weight and prolonged suffering, but exhibiting no signs of disease other than the rectal mischief. gave a history of typhoid fever ten years previously and some chronic bronchitis. Her present trouble began in September, 1904, with a fistula of moderate size. She was-during 1905 and 1906-treated at St. Bartholomew's Hospital, being admitted into the in-patient department during the October of each year. During the whole of this time there was a copious purulent discharge which progressively increased. In February, 1907, she came as an out-patient to St. Mark's Hospital and in April she was admitted as an in-patient. Her wound then was an extensive gap situated dorsally and to the left of the anus, involving the mucous membrane of about from half an inch to an inch of the rectum. Owing to the separation of the cut surfaces of the sphincter ani and to the extensive fibrosis around, there was no power of that muscle and therefore no control. The surface of the wound was unhealthy in appearance, having that peculiar aspect known as "callous." There was an abundant discharge of thin, offensive pus which had produced an irritable condition of the surrounding skin. On April 9th, 1907, a branch tract of the fistula was opened up, preparatory to an attempt to diminish the gap and restore the continuity of the sphincter. 19 days later such an effort was made, the wound being freshened and brought together with sutures. Some suppuration occurred necessitating the removal of three stitches, the wound then being a little smaller than before. For a fortnight following the operation the temperature ranged. between normal and $101^{\circ} \mathrm{F}$, then for a week it remained within a degree of 98.4 ; during the whole of which three weeks the wound continued to discharge freely, its surface retaining the sluggish appearance. The temperature now became irregular, ranging through two degrees; at the same time the patient assumed that inert listless condition commonly seen in typhoid fever. Soreness of the mouth was complained of, and on examination the gums were found to be tender and swollen, the tongue clean, and the pulse 80 . The patient was given an alum mouthwash, whilst careful attention was enjoined as regards the cleanliness of the teeth. The temperature now became intermittent, the excursion being $3^{\circ}$. After this condition had lasted for seven days hæmorrhage began from the gums, which soon became profuse. On the following day blood began to flow from the rectal wound, soaking the dressings which were constantly changed. Simultaneously a purpuric rash appeared upon the face, shortly followed by petechiæ of wider distribution. The arms, especially the shoulders, and the legs, especially the buttocks and thighs, were mostly affected, the trunk being almost free from spots. With the onset of the bleeding the temperature became steady; the pulse was weak and irregular and it varied between 90 and 100 , whilst the respirations were 28 per minute. In the course of 24 hours four half-drachm doses of calcium chloride were given, a hazeline mouthwash was used frequently, and at the onset of bleeding a hypodermic injection of ergotinine citrate was administered. At the point of entrance of the needle a bæmatoma of the size of half a walnut was produced. After the læmorrhage had continued for three days it gradually ceased. The patient was then given an alum mouthwash and a mixture containing iron and quinine, whilst two lemons and extra vegetables were added to her daily diet. There was no return of hæmorrhage, the temperature and pulse became satisfactory, the mouth resumed its normal condition, and the patient's general condition greatly improved; her weight increasing, the mental outlook becoming bright and active, and her pallor less marked. Associated with this improvement there was a corresponding change in the wound, the reparative power of the tissues increasing, and healing being accelerated. Three weeks later the patient was able to go to the seaside, if not cured very considerably improved.

Three points of interest seem to arise out of this case. 1. The occurrence of scurvy in a patient whose food had been the same as customary among people of her class, for on special inquiry she stated that she was in the habit of taking plenty of good and fresh food. Moreover, she had been in hospital a month, where her diet was a plentiful one of milk, beef-tea, custard, jelly, and so on, before the onset of the scorbutic symptoms. 2. The possibility of the retardation of healing seen in certain forms of long-standing "callous" wounds being due to a scorbutic diathesis. 3. The possibility of the long-continued suppuration and mental distress being the cause of this diathesis, a vicious circle thus being produced.

I am indebted to Mr. F. Swinford Edwards, senior surgeon to St. Mark's Hospital, for permission to report this case.

\section{PRELIMINARY NOTE ON A LEUCOCYTO. ZOON FOUND IN THE BLOOD OF THE RED GROUSE (LAGOPUS SCOTICUS).}

By C. G. SELIGMANN, M.D., M.R.C.P. Lond, BACTERIOLOGIST TO THE COMMISSION ON GROUSE DISEASE, AND

LOUIS W. SAMBON, M.D. NAPLES, F.Z.S., LECTURER TO THE LONBON SCHOOL OF TROPICAL MEDICINE.

WHILE examining blood films of a number of grouse sent to Dr. E. A. Wilson, field observer to the Grouse Commission, as birds suffering from grouse disease, a protozoal blood parasite of a genus hitherto unknown in the Tetraonida was discovered. The bird in which it was seen 